\title{
La constante búsqueda de una voz propia en la poesía de Julia Ruíz
}

Recibido: 12.07.2017 / Aprobado: 02.10.2017

Por Julia Ruiz

Julia Ruiz (Santa Fe, Argentina, 1986), Doctoranda en Letras en la Facultad de Humanidades y Ciencias de la Universidad Nacional del Litoral, miembro del CEDINTEL (Centro de Investigaciones Teórico Literarias) de la misma universidad. Primer Premio de Poesía en el Certamen "José Rafael López Rosas" (Santa Fe, 2011), Primer Premio en el Certamen Literario Inter Universidades de América Latina (Brasil, 2012) y el Primer Premio en el Certamen de Poesía Saint Jordí (España, 2013). Ha publicado cinco obras. Presidenta de la Asociación Cultural 'El Puente' y escritora de los grupos 'Emparche, ensamble de percusión'y 'Palabras que suenan' de la ciudad de Santa Fe.

Desde sus comienzos la obra de Julia Ruiz está signada por la constante búsqueda de una voz propia: la misma se manifiesta desde un tono confidencial, el uso del lenguaje cotidiano, una tópica afectiva, una mirada macro y micro sobre los objetos del mundo. Desde un poema a una gota de lluvia hasta la reminiscencia ancestral, la poesía de Julia no deja de preguntarse y de preguntarnos por los límites y las tensiones entre la literatura y la vida, por las diferentes maneras de crear, por los vínculos entre autor y lector, por el profundo poder de la palabra poética.

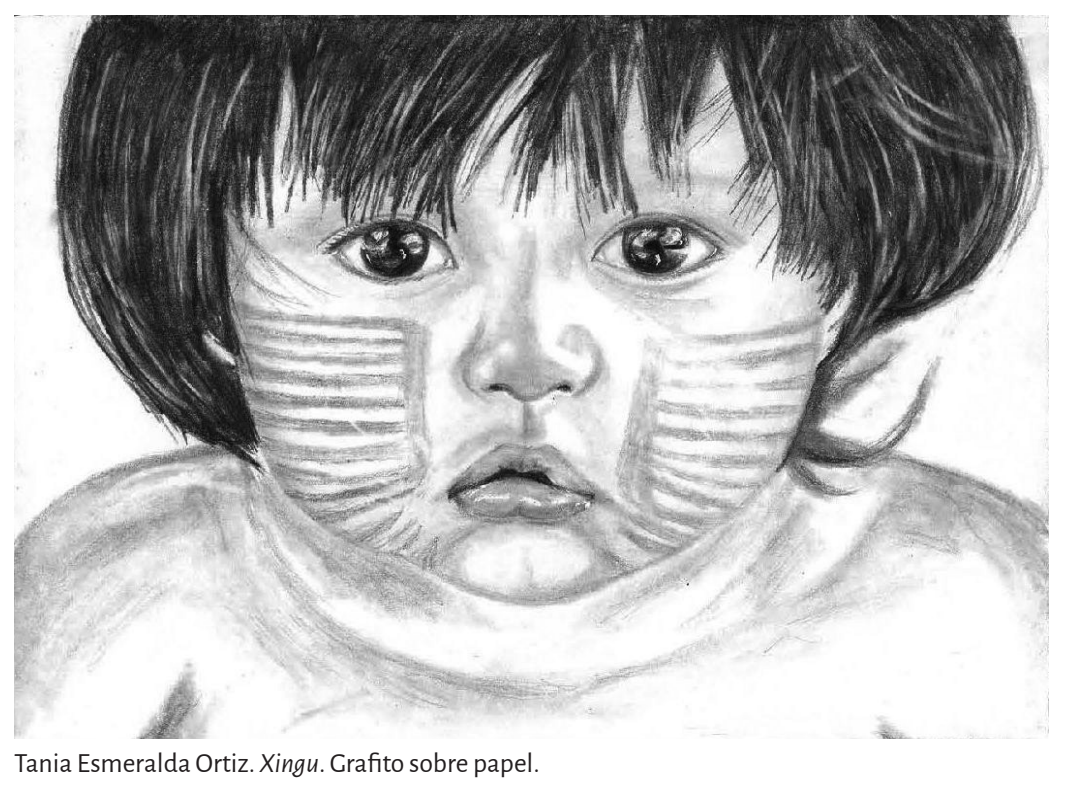

La utilización espacial también es una constante en la producción de Julia, desde la cual se producen ecos y silencios significantes. Asimismo, la presencia de voces referentes de la literatura mundial dicen presente entre las páginas, a través de epígrafes o citas encubiertas que nos ponen a jugar como lectores en un laberinto textual de significaciones. una mirada desde la alcantarilla puede ser una visión del mundo

la rebelión consiste en mirar una rosa hasta pulverizarse los ojos

decía Alejandra Pizarnik, y la poesía de Julia sigue ese credo; una mirada desde el margen de las páginas que deconstruye los objetos cotidianos para volverlos, una y otra vez, poesía. 


\section{Literatura}

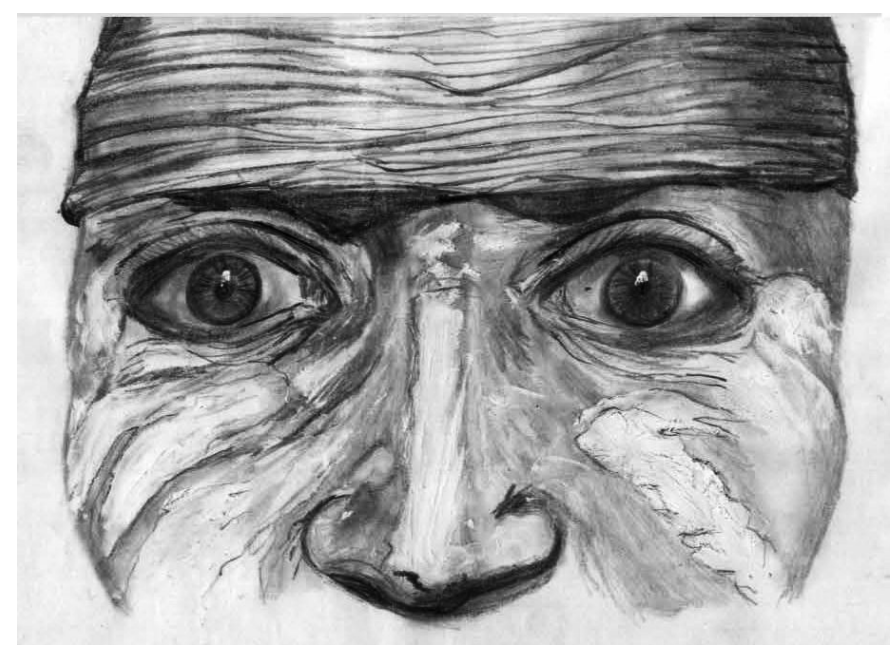

Tania Esmeralda Ortiz. Marcas. Técnica mixta sobre papel.

\section{Selección de poemas de Julia Ruíz}

\section{Palabras de familia}

\section{I}

A veces me pregunto

de dónde salió esta forma de transcurrir

quién plantó en mí

la necesidad del verbo

qué ancestro me susurra

palabras de familia

qué voz que no conozco

me habla

yen un murmullo mecuenta

historias cotidianas

revoluciones diminutas

\section{II}

No sé cómo eran mis ancestros

no conozco sus mañas

sus torpezas

sus simplezas

sus cotidianías

No sé si tenían

los pies en la tierra

o un vaivén diáfano sólo puedo imaginarlos

anclados en esta estampa de eternidad

una foto cuarteada

deañosy lejanías

III

No estuve en los planes

No fui marcada

en las cartografías

soy una tangente abierta

después del tiempo

\section{IV}

No somos más

que una repetición de huesos que se mueven por la tierra una carne labrada germinada cosechada y esparcida

\section{V}

Los miro mirar en la foto borro de a poco esa fija eternidad y sacudo el polvo a sus miradas posadas comoal descuido en mí

para moverse por el mundo 


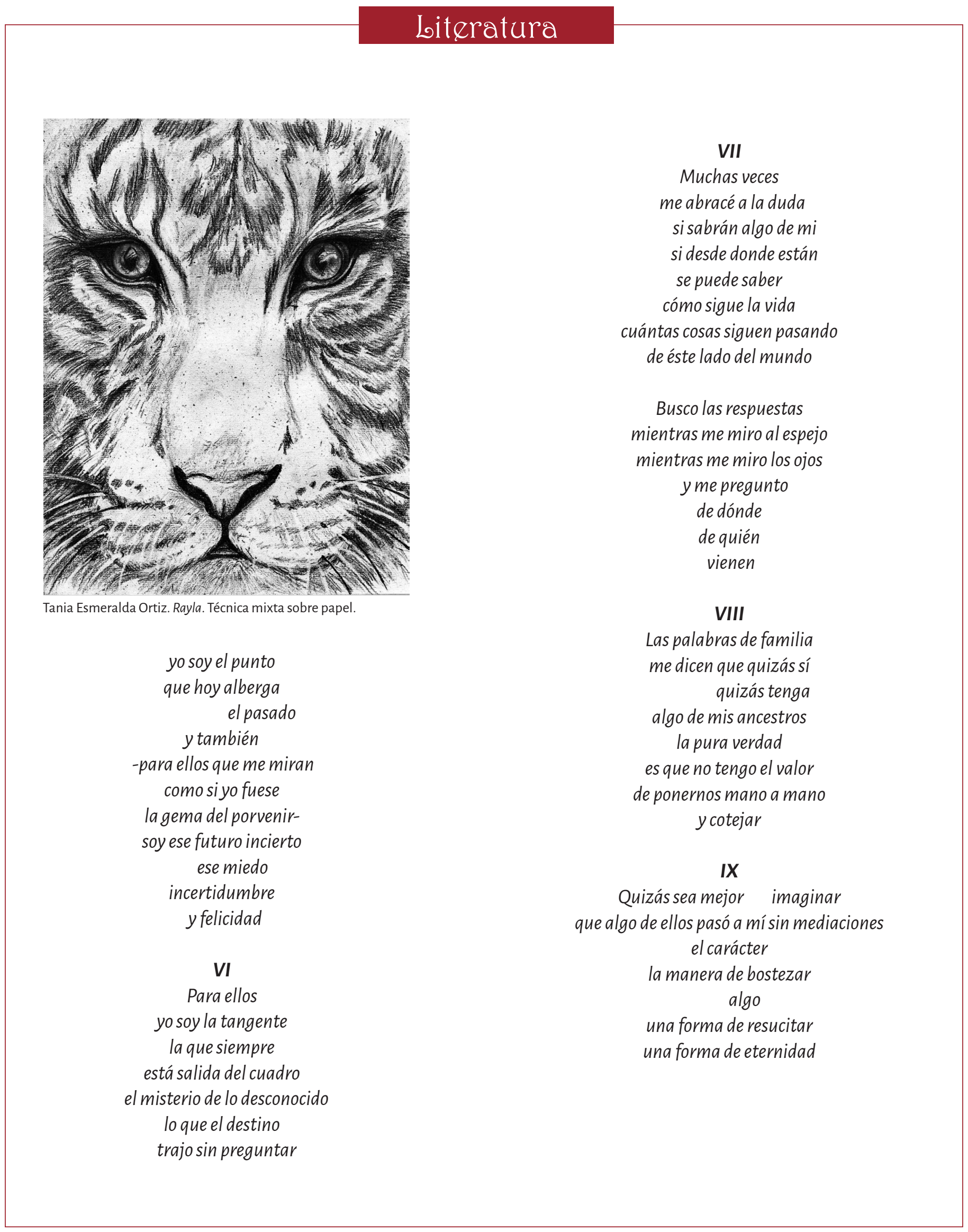




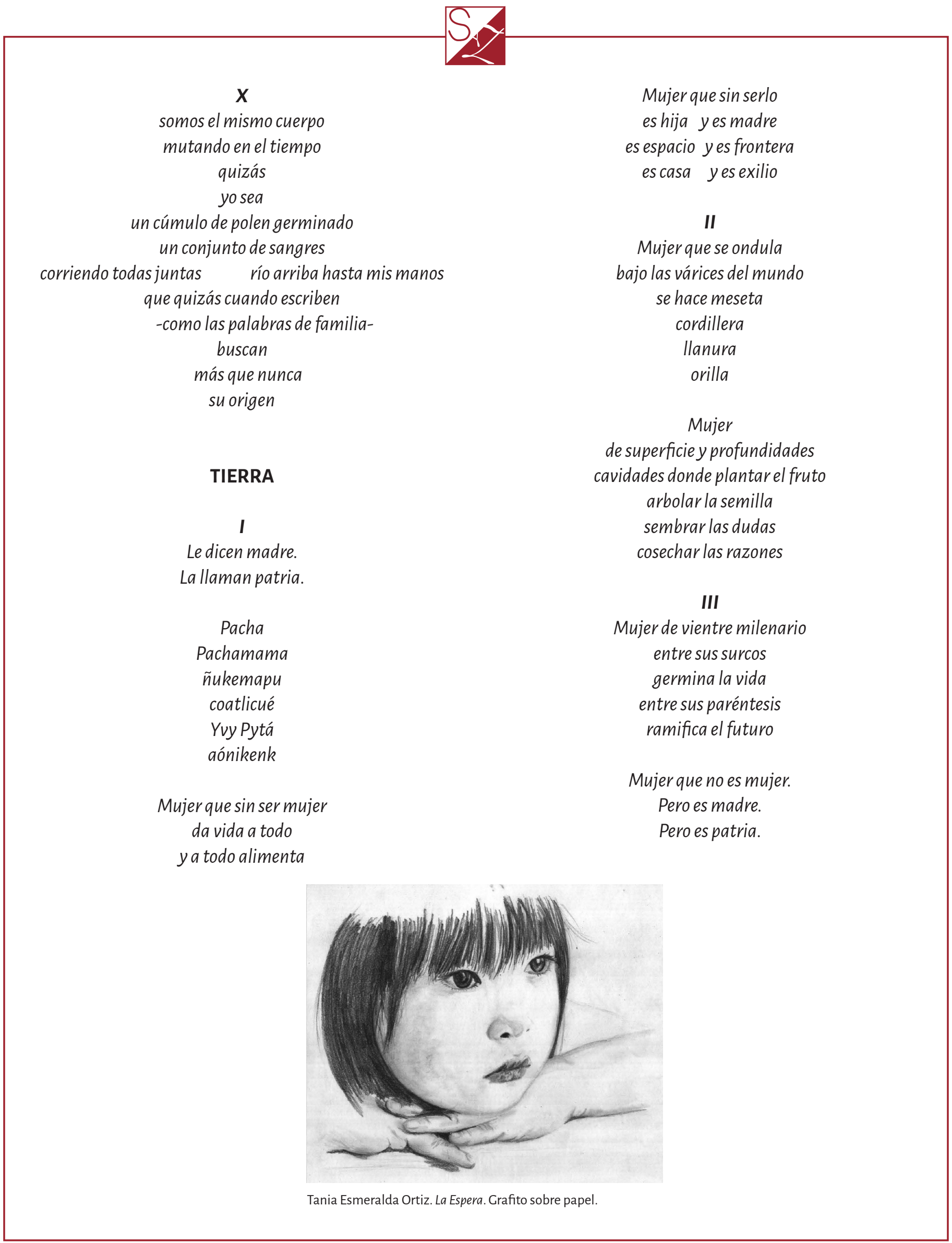

